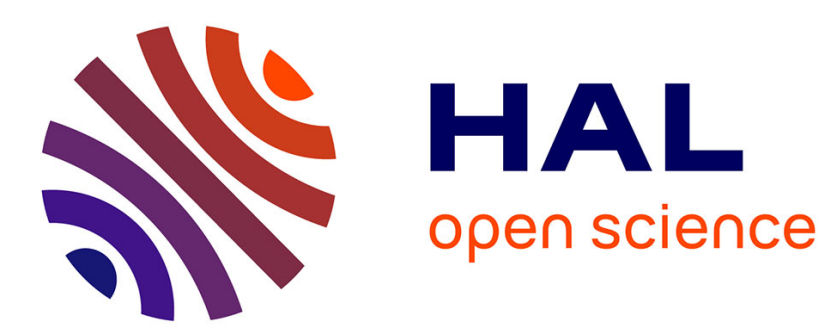

\title{
0.5-V 50-mV-Swing 1.2-GHz 28-nm-FD-SOI 32-bit Dynamic Bus Architecture with Dummy Bus
}

Khaja Ahmad Shaik, Kiyoo Itoh, Amara Amara

\section{To cite this version:}

Khaja Ahmad Shaik, Kiyoo Itoh, Amara Amara. 0.5-V 50-mV-Swing 1.2-GHz 28-nm-FD-SOI 32bit Dynamic Bus Architecture with Dummy Bus. ISQED, Mar 2016, Santa Clara, United States. hal-01254227

\section{HAL Id: hal-01254227 \\ https://hal.science/hal-01254227}

Submitted on 11 Jan 2016

HAL is a multi-disciplinary open access archive for the deposit and dissemination of scientific research documents, whether they are published or not. The documents may come from teaching and research institutions in France or abroad, or from public or private research centers.
L'archive ouverte pluridisciplinaire HAL, est destinée au dépôt et à la diffusion de documents scientifiques de niveau recherche, publiés ou non, émanant des établissements d'enseignement et de recherche français ou étrangers, des laboratoires publics ou privés. 


\title{
0.5-V 50-mV-Swing 1.2-GHz 28-nm-FD-SOI 32-bit Dynamic Bus Architecture with Dummy Bus
}

\author{
Khaja Ahmad Shaik, Kiyoo Itoh, and Amara Amara \\ Institut supérieur d'électronique de Paris (ISEP), 10 Rue Vanves, Issy-les-Moulineaux, France. kshaik@isep.fr
}

\begin{abstract}
To achieve a $0.5-\mathrm{V}$ low-power high-speed robust bus, a dynamic bus architecture, combined with a dynamic driver and a dynamic receiver for small leakage current with stacked MOSFETs, is proposed. In particular, the dynamic driver enables high speed even at $0.5 \mathrm{~V}$ with increased gateover-drive by changing the power lines from $V_{\mathrm{DD}} / 2$ in the standby mode to $V_{\mathrm{DD}}$ in the active mode. It further speeds up with the help of another proposal of a dummy bus for tracking the bus-voltage detecting point for reducing the bus swing. Robustness of each proposal is investigated by Monte Carlo simulation. Then, a $0.5-\mathrm{V}$ 28-nm-FD-SOI 32-bit bus architecture using the proposals is evaluated by simulation. The power-supply bounce noise and the reduction are also investigated here through the layout. As a result, it turns out that the architecture has a potential of operating a $1-\mathrm{pF}$ bus at a $50-\mathrm{mV}$ swing, $1.2 \mathrm{GHz}$, and a standby current of $1.1 \mu \mathrm{A}$, with x3-5 faster and more than two-order lower standby current than the conventional static architecture.
\end{abstract}

Keywords-0.5-V 50-mV-swing dynamic bus, stacked MOSFETs, dummy bus, 32-bit dynamic bus architecture

\section{Introduction}

Low-power bus architectures for intra- and inter-chip communication have been strongly needed to cope with the ever-increasing interconnect power dissipation caused by larger interconnect capacitances [1]. Indeed, data-bus lines, address lines, control lines, and precharge lines running across a chip inevitably increase the capacitances with larger scale integration of chips. In addition, the number of the lines, especially for data buses in RAMs and MPUs, increases with the ever-stronger need for higher throughput, exemplified by as large as 1024 [2] for 3D integration such as ThroughSilicon-Via (TSV)-3D chips. Such buses will continue to be indispensable even with power-supply $\left(V_{\mathrm{DD}}\right)$ and device scaling, calling for new circuits as well as low-capacitance interconnect technology. The most effective way is to lower the voltage swing on the bus. In line with this, many attempts have been made so far despite some drawbacks (such as limited reduction of the swing, and complicated and large area) being involved. Good examples are a flip-flop receiver [3], current-mode signaling [4], and differential buses [5]. Of these, N.C. Svensson's static bus architecture [6] is simple and most promising with respect to low-voltage-swing capability thanks to an inverter-amplifier in a receiver. Even so, the basic characteristics and design issues remain unknown, although optimization of the power dissipation was investigated. The most serious issue of the attempts, however, is the fact that they were evaluated at $V_{\mathrm{DD}}$ higher than $1 \mathrm{~V}$ and with device feature sizes larger than $0.13 \mu \mathrm{m}$. Obviously, considering that the state-of-the-art $V_{\mathrm{DD}}$ and devices for SoCs are $0.6 \mathrm{~V}$ and 14 $\mathrm{nm}$ even at the commercial base [7], the bus architectures must keep up with the scaling because they will be eventually embedded in such SoCs. Hence, the ever-increasing subthreshold leakage (off) current with reducing $V_{\mathrm{t}}$ and degraded robustness by $V_{\mathrm{t}}$-variations with device scaling [8] are emerging issues for the bus design. Well-known stackedMOSFETs for low-leakage current are thus indispensable. Moreover, the use of fully-depleted SOI MOSFETs [9] is vital for smaller $V_{\mathrm{t}}$-variations. Note that using bulk MOSFETs may be intolerable, considering the standard deviation $\left(\sigma V_{\mathrm{t}}\right)$ of the local $V_{\mathrm{t}}$-variation [8] given as $\sigma V_{\mathrm{t}}=A_{\mathrm{vt}} /(L W)^{1 / 2}\left(A_{\mathrm{vt}}\right.$; the Pelgrom coefficient). This is because the necessary channel width $W \mathrm{~s}$ are expected to be almost quadrupled for a given $\sigma V_{\mathrm{t}}$. Here, as for the global $V_{\mathrm{t}}$-variation, which influences speed, the so-called back plain control by detecting the average $V_{\mathrm{t}}$ [10] is effective. In addition to the above scaling issues, to the best of our knowledge, multi-bit bus architectures, indispensable for data bus in DRAMs and embedded SRAMs in SoCs, remain unreported.

In this paper, first, design issues of Svensson's conventional static bus (S-BUS) with the inverter-amplifier are clarified. Then, a dynamic bus architecture (D-BUS) to cope with the issues is proposed. It consists of a dynamic driver, a dynamic receiver, and a dummy bus for smaller bus swing for high speed and low power. Some of them are then evaluated in terms of speed and robustness by Monte Carlo simulation. Noise issue is also briefly discussed. Finally, a 32-bit bus architecture using the proposals and 28-nm FD-SOI MOSFETs is evaluated by simulation and the layout.

\section{Design Issues of Conventional Static Bus}

Fig. 1 shows the conventional S-BUS [6]. The bus consists of a gate-source offset-driven CMOS inverter [3] for a driver (DRV), and amplifiers with symmetric CMOS inverters (i.e., with $W_{\mathrm{p}} / W_{\mathrm{n}} \cong 2.5$ ) for a receiver (REC), each trip point of which is set to $V_{\mathrm{DD}} / 2$ for maximizing the amplification. DRV operates at power supplies of $\left(V_{\mathrm{DD}} / 2+V_{\mathrm{s}}\right)$ and $\left(V_{\mathrm{DD}} / 2-V_{\mathrm{s}}\right)$, so the bus is biased at $V_{\mathrm{DD}} / 2$ and swings at signal components $\pm V_{\mathrm{s}}$ that corresponds to the input IN data " 1 " $(\mathrm{H})$ or " 0 " $(\mathrm{L})$. The first inverter $\mathrm{IV}_{1}$ amplifies and discriminates $\pm V_{\mathrm{s}}$, referring to $V_{\mathrm{DD}} / 2$. For example, at $V \mathrm{~s}=50 \mathrm{mV}$, a signal component +50 $\mathrm{mV}$ superposed on the $V_{\mathrm{DD}} / 2$ (point $\mathbf{m}$ ) is amplified and a low enough voltage (point $\mathbf{l}$ ) is thus outputted at $\mathrm{OUT}_{1}$. In contrast, 

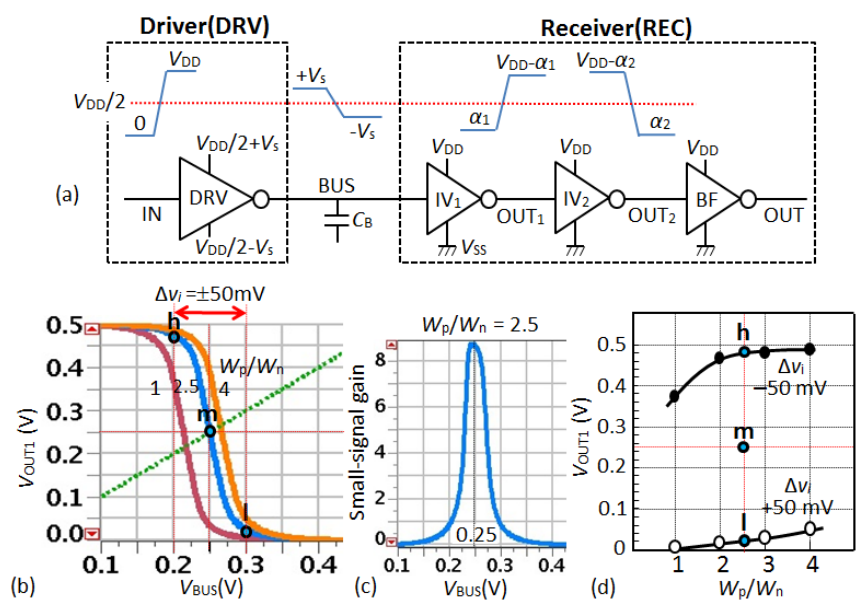

Fig. 1 (a) Conventional static bus architecture (S-BUS) [3, 6], and (b) $\mathrm{IV}_{1}$-characteristics.

another signal component $-50 \mathrm{mV}$ is amplified and a high enough voltage of about $0.5 \mathrm{~V}$ (point $\mathbf{h}$ ) is available at $\mathrm{OUT}_{1}$.

There are two major issues, namely, extremely slow speed of DRV due to the power-supply setting of $V_{\mathrm{DD}} / 2 \pm V_{\mathrm{s}}$, and large DC current of REC due to the static operation. For example, the gate-over-drive $\left(\mathrm{GOD}_{\mathrm{d}}\right.$, namely, $\left.V_{\mathrm{GS}}-V_{\mathrm{t}}\right)$ of $\mathrm{DRV}$ MOSFETs when driving BUS is as low as $0.046 \mathrm{~V}$ at $V_{\mathrm{DD}}=0.5$ $\mathrm{V}, V_{\mathrm{s}}=50 \mathrm{mV}$, and $V_{\mathrm{t}}=0.254 \mathrm{~V}$ (i.e., low $V_{\mathrm{t}}(\mathrm{LVT})$ ) because it is given as $V_{\mathrm{DD}} / 2+V_{\mathrm{s}}-V_{\mathrm{t}}$. Such small $\mathrm{GOD}_{\mathrm{d}}$ also makes the speed quite sensitive to $V_{\mathrm{t}}$-variations. The large $\mathrm{DC}$ current comes from operations at small gate voltages of about $V_{\mathrm{DD}} / 2$. Fortunately, the succeeding inverters operating at higher $V_{\mathrm{GS}}$ with more amplified input voltage consume much small current. DRV itself also consumes a small enough current, because the $V_{\mathrm{t}}$ is effectively a regular $V_{\mathrm{t}}(\mathrm{RVT}=0.454 \mathrm{~V})$ that ensures a low enough off-leakage current, since the source of the LVT MOSFET is at $0.2 \mathrm{~V}$.

\section{Proposed Dynamic Bus Architecture}

Fig. 2 shows a proposed dynamic bus architecture (D-BUS) composed of a dynamic DRV (D-DRV), a dynamic REC (DREC), and the dummy bus architecture (DM-BSA) to generate precharge pulses $\mathrm{P}$ and $/ \mathrm{P}$ to control D-DRV and D-REC. Fig. 2(c) summarizes the features. Note that nominal channel widths $W_{\mathrm{s}}$ of all the circuits must be carefully chosen in terms of the speed and robustness focusing on $V_{\mathrm{t}}$-variations under a channel length of $30 \mathrm{~nm}$.

\section{A. Dynamic Driver (D-DRV)}

It consists of a CMOS driver (DRV), a power supply controller (PSC), and a BUS-precharge accelerator (ACC). Note that setting the $V_{\mathrm{t}}$ of $\mathrm{M}_{\mathrm{d}}$ to zero (ZVT) makes the whole CMOS inverter (composed of DRV, $\mathrm{M}_{\mathrm{s}}$ and $\mathrm{M}_{\mathrm{d}}$ ) symmetric as much as possible. Here, the power lines, DDL and SSL of $\mathrm{DRV}$, are at $V_{\mathrm{DD}}$ and at $0 \mathrm{~V}$, respectively, at the first half (active) of cycle, while they are at $V_{\mathrm{DD}} / 2$ at the second half precharge) of cycle. The bus (BUS) is thus charged up with $M_{d}$ and $\mathrm{M}_{\mathrm{pd}}$ or discharged with $\mathrm{M}_{\mathrm{s}}$ and $\mathrm{M}_{\mathrm{nd}}$, depending on the input (IN) voltage. There is no leakage current during precharge
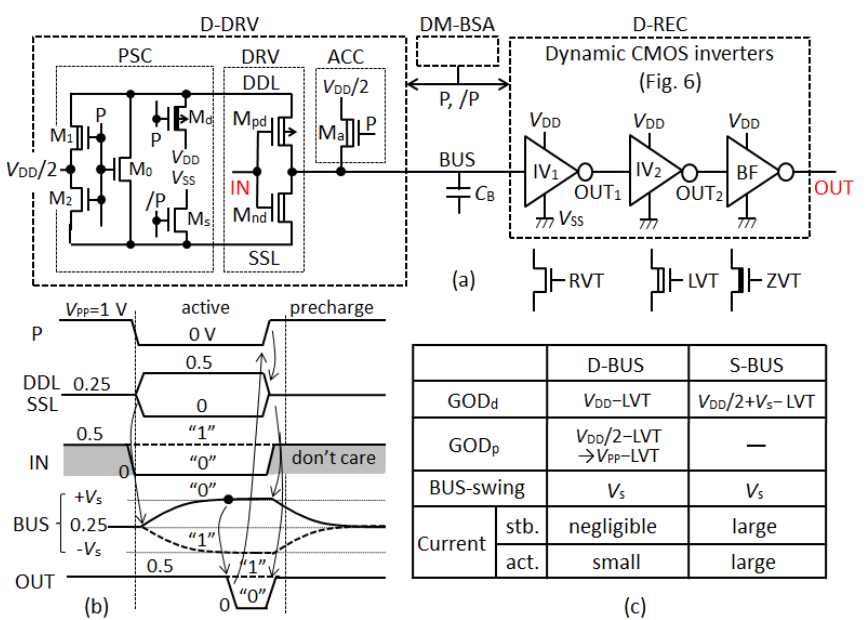

\begin{tabular}{|c|c|c|c|}
\hline & D-BUS & S-BUS \\
\hline GODd $_{d}$ & $V_{D D}-\mathrm{LVT}$ & $V_{\mathrm{DD}} / 2+V_{\mathrm{s}}-\mathrm{LVT}$ \\
\hline \multicolumn{2}{|c|}{$\mathrm{GOD}_{\mathrm{p}}$} & $\begin{array}{c}V_{\mathrm{DD}} / 2-\mathrm{LVT} \\
\rightarrow V_{\mathrm{PP}}-\mathrm{LVT}\end{array}$ & - \\
\hline \multicolumn{2}{|c|}{ BUS-swing } & $V_{\mathrm{s}}$ & $V_{\mathrm{s}}$ \\
\hline \multirow{2}{*}{ Current } & stb. & negligible & large \\
\cline { 2 - 4 } & act. & small & large \\
\hline
\end{tabular}

(c)

Fig. 2 (a) Dynamic bus architecture (D-BUS), (b) timing diagram, and (c) features. RVT; regular $\mathrm{V}_{\mathrm{t}}(=0.454 \mathrm{~V})$, LVT; low $\mathrm{V}_{\mathrm{t}}(=0.254$ $\mathrm{V}), \mathrm{ZVT}$; zero $\mathrm{V}_{\mathrm{t}}(=0 \mathrm{~V})$. $\mathrm{GOD}_{\mathrm{d}}$ and $\mathrm{GOD}_{\mathrm{p}}$; GODs when driving and precharging BUS, respectively.

periods due to DDL and SSL being at $V_{\mathrm{DD}} / 2$. Hence, DRV accepts even ZVT-MOSFETs for maximizing BUS-speed. Moreover, BUS is more quickly driven than S-BUS because $\mathrm{GOD}_{\mathrm{d}}$ when $\mathrm{M}_{\text {nd }}$ or $\mathrm{M}_{\mathrm{pd}}$ drives BUS increases from $0.046 \mathrm{~V}$ of S-BUS to $0.246 \mathrm{~V}\left(=V_{\mathrm{DD}}-\mathrm{LVT}\right)$. Obviously, a smaller $V_{\mathrm{s}}$ makes BUS faster with lower dynamic power, as also explained later. It is achieved by stopping bus-driving on the way going to $V_{\mathrm{DD}}$ or $V_{\mathrm{SS}}$ from $V_{\mathrm{DD}} / 2$ with controlling the pulse widths of $\mathrm{P}$ and $/ \mathrm{P}$. Unfortunately, however, BUS-prechaging is slow because $\mathrm{GOD}_{\mathrm{p}}$ of $\mathrm{M}_{\mathrm{nd}}$ or $\mathrm{M}_{\mathrm{pd}}$ when precharging BUS is as low as $V_{\mathrm{DD}} / 2-\mathrm{LVT}(\cong 0)$. This drawback is remedied by the help of ACC operating at $V_{\mathrm{PP}}(=1 \mathrm{~V})$, since the resultant $\mathrm{GOD}_{\mathrm{p}}$ increases to $V_{\mathrm{PP}}-\mathrm{LVT}(=0.496 \mathrm{~V})$. Consequently, the BUS driving speed and precharging speed are determined by DRV and PSC, and ACC, respectively. The sum of both speeds is almost equal to the minimum cycle time $t_{\text {cmin }}$.

In addition to the high speed, smaller speed variations of DDRV thanks to larger GOD are noteworthy. The variations can be evaluated with the offset voltage, $V_{\text {off }}(\mathrm{DRV})$, defined as the output voltage ( $\left.V_{\mathrm{BUS}}\right)$ deviated from $V_{\mathrm{DD}} / 2$ when the input of DRV (IN) is at $V_{\mathrm{DD}} / 2$ (see Figs. 3(a) and (b)). Fig. 4(a) depicts
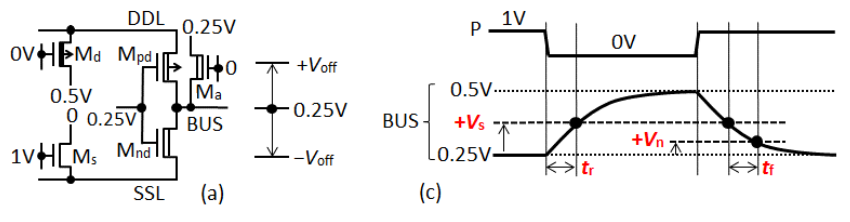

(c)

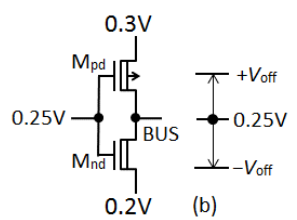

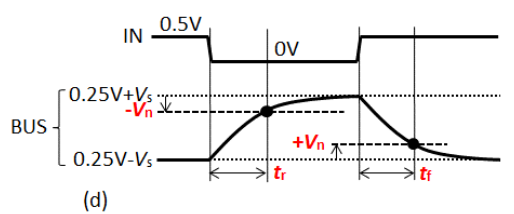

Fig. 3 Simulation conditions for $\mathrm{V}_{\text {off }}(\mathrm{DRV})$ of (a) D-DRV and (b) SDRV, and speeds of (c) D-DRV and (d) S-DRV for input "0". Minimum cycle $t_{\text {cmin }} \cong t_{\mathrm{r}}+t_{\mathrm{f}}$ for D-BUS, and $t_{\mathrm{f}}\left(\cong t_{\mathrm{r}}\right)$ for S-BUS. 

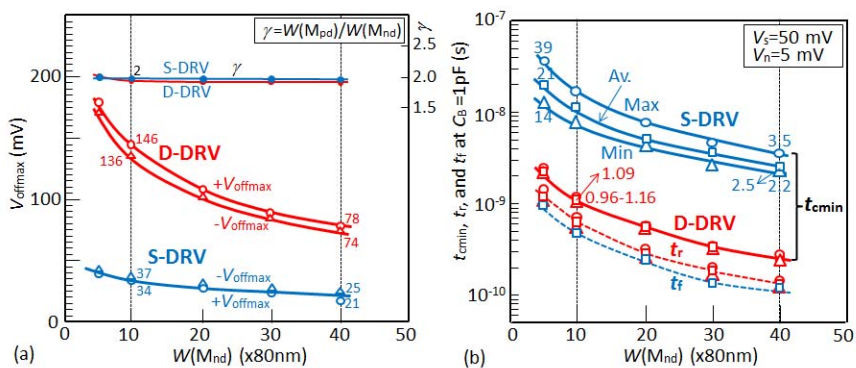

Fig. 4 (a) $V_{\text {offmax }}$ and (b) BUS-driving speeds for $W\left(\mathrm{M}_{\mathrm{nd}}\right)$.

$V_{\text {off }}(\mathrm{DRV})$ vs. $W\left(\mathrm{M}_{\mathrm{nd}}\right)$ when the $V_{\mathrm{t}}$-variation is taken into account by Monte Carlo simulation with 1,000 samples. Here, $W\left(\mathrm{M}_{\mathrm{pd}}\right)$ was trimmed whenever $W\left(\mathrm{M}_{\mathrm{nd}}\right)$ was changed, so DRV became always symmetric. Other $W$-ratios to $W\left(\mathrm{M}_{\mathrm{nd}}\right)$, however, are constant, namely, $W\left(\mathrm{M}_{\mathrm{d}}\right) / W\left(\mathrm{M}_{\mathrm{nd}}\right)=1.25, W\left(\mathrm{M}_{\mathrm{s}}\right) / W\left(\mathrm{M}_{\mathrm{nd}}\right)=$ $0.5, W\left(\mathrm{M}_{0}-\mathrm{M}_{2}\right) / W\left(\mathrm{M}_{\mathrm{nd}}\right)=0.2$, and $W\left(\mathrm{M}_{\mathrm{a}}\right) / W\left(\mathrm{M}_{\mathrm{nd}}\right)=2$ for $\mathrm{D}-$ DRV, while $W\left(\mathrm{M}_{\mathrm{pd}}\right) / W\left(\mathrm{M}_{\mathrm{nd}}\right) \cong 2$ for S-DRV. Obviously, $V_{\text {off }} \mathrm{S}$ decrease with increasing the $W$, as expected from the abovementioned expression on $\sigma V_{\mathrm{t}}$. Although D-DRV has larger $V_{\text {off }}(\mathrm{DRV})$ due to additional small $\mathrm{M}_{\mathrm{d}}$ and $\mathrm{M}_{\mathrm{s}}$, the drawback is offset by larger GOD. Indeed, as seen in Fig. 4(b), the signal developing time $t_{\mathrm{r}}$, the precharge time $t_{\mathrm{f}}$, and thus $t_{\mathrm{cmin}}$, defined at $V_{\mathrm{s}}=50 \mathrm{mV}$ and $V_{\mathrm{n}}=5 \mathrm{mV}$ (noise) for " 0 " input, as in Figs. 3 (c) and (d), are shorter with more reduced variation than those of S-DRV. Fig. 5 shows the signal characteristics. Obviously, $t_{\mathrm{r}}$ becomes longer with increasing $V_{\mathrm{s}}$, as mentioned before, calling for reduction of the necessary $V_{\mathrm{s}}$ for fast cycle. The reduction strongly influences the cycle time, since BUS is slowly driven due to a large $C_{\mathrm{B}}$. As for $t_{\mathrm{f}}$, it becomes longer with $V_{\mathrm{n}}$ for a given $V_{\mathrm{s}}$ of $50 \mathrm{mV}$, due to need for longer precharging time. Here, $V_{\mathrm{n}}$ works as noise for the next cycle with the incomplete precharging voltage. Thus, faster BUSprecharging is necessary for faster cycle with the help of the accelerator ACC.

Here, let's investigate the robustness of a BUS with $W\left(\mathrm{M}_{\mathrm{nd}}\right)$ $=10 \times 80 \mathrm{~nm}$, when a 841-ps-cycle pulse $(\mathrm{P})$ with an active pulse width $t_{\mathrm{w}}$ of $353 \mathrm{ps}$ and an off-pulse width $t_{\text {off }}$ of $488 \mathrm{ps}$ is provided by the dummy bus (DM-BSA), as discussed later. Since $t_{\mathrm{w}}$ and $t_{\mathrm{off}}$ are almost equal to the BUS-driving speed $t_{\mathrm{r}}$ and precharging speed $t_{\mathrm{f}}$, respectively, the BUS generates a $V_{\mathrm{s}}$ of $37 \mathrm{mV}$ and a $V_{\mathrm{n}}$ less than $5 \mathrm{mV}$, as seen in Fig. 5. Hence, if the total noise including other noise components is less than 32 $\mathrm{mV}(=37-5)$, the BUS-stability is ensured.
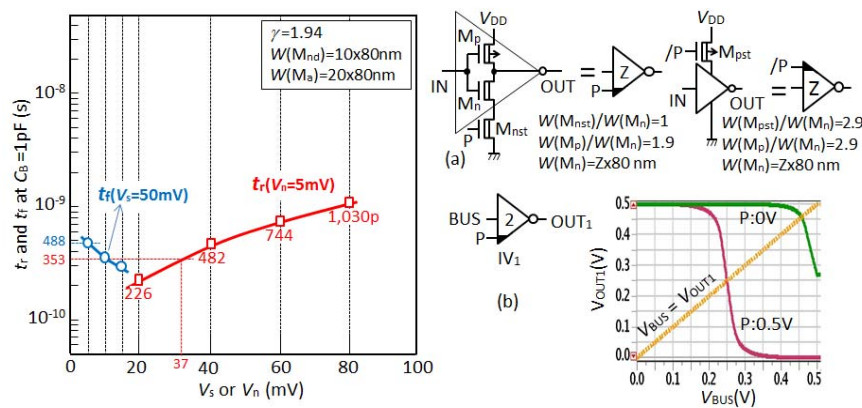

Fig. 5 Signal characteristics of D-DRV. Fig. 6 (a) Stacked-MOSFETinverters in REC and symbols, (b) transfer curves of $\mathrm{IV}_{1}$.
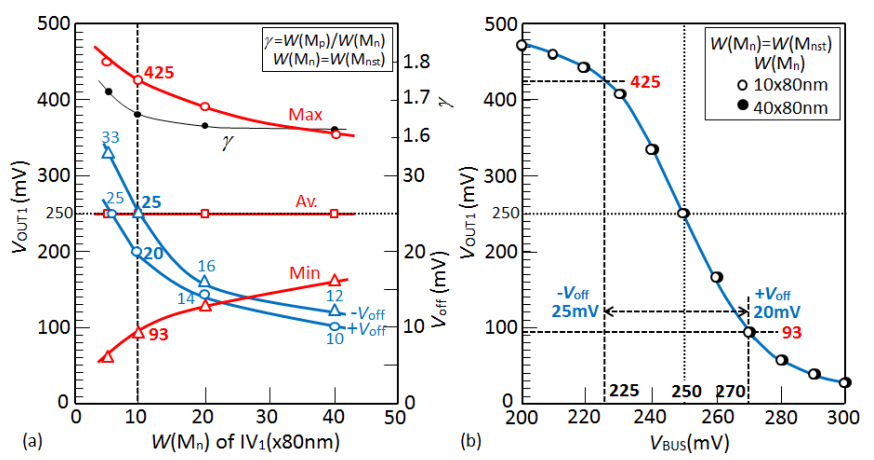

Fig. 7 (a) $V_{\text {OUT1 }}$ and $V_{\text {off }}$ converted to BUS, and (b) $V_{\text {BUS }}$ Vs. $V_{\text {OUT1 }}$ for $W\left(\mathrm{M}_{\mathrm{n}}\right) . \mathrm{M}_{\mathrm{n}} ;$ nMOSFET in $\mathrm{IV}_{1}$.

\section{B. Dynamic Receiver (D-REC)}

It uses the same circuit and LVT MOSFETs as S-BUS, except for the dynamic operation. Major concerns here are the large DC current and the offset voltage $V_{\text {off }}(\mathrm{REC})$ of $\mathrm{IV}_{1}$, both of which are not imposed on the succeeding stages due to amplified gate-voltages. The current is reduced by a dynamically-operated stacked-MOSFET (e.g., $M_{\text {nst }}$ in Fig. 6(a)). In this circuit, while the pulse $\mathrm{P}$ is at $0.5 \mathrm{~V}$ at the first half of cycle, $M_{n s t}$ turns on for active operation with a quite large current due to operating at about $V_{\mathrm{DD}} / 2$. At the second half of cycle with $\mathrm{P}$ at $0 \mathrm{~V}$ (precharge period), the current is reduced to a negligible level (e.g., from $8 \mu \mathrm{A}$ to $31 \mathrm{nA}$, see Fig. $8(c))$ that is equal to a small subthreshold current of $M_{n s t}$. Hence, the current is almost halved in the active mode at a $50 \%$ duty cycle, while negligible in the standby mode. The more detail will be discussed later. As for $V_{\text {off }}($ REC), Fig. 7 depicts the $\mathrm{IV}_{1}$-output and variations vs. $W\left(\mathrm{M}_{\mathrm{n}}\right)$, taken by Monte Carlo simulation. $V_{\text {off }}\left(\right.$ REC) is the deviation from $V_{\mathrm{DD}} / 2$, as mentioned previously. For example, for $W\left(\mathrm{M}_{\mathrm{n}}\right)=W\left(\mathrm{M}_{\mathrm{nst}}\right)=$ $10 \mathrm{x} 80 \mathrm{~nm}, V_{\text {out } 1}$ ranges from $425 \mathrm{mV}$ to $93 \mathrm{mV}$ (see Fig. 7(a)). They correspond to $225 \mathrm{mV}$ and $270 \mathrm{mV}$ if converted to the input (i.e., BUS) (see Fig. 7(b)), implying that $V_{\text {off }}($ REC)s are $25 \mathrm{mV}$ and $+20 \mathrm{mV}$, respectively. Since $V_{\text {off }}(\mathrm{REC})$ is the
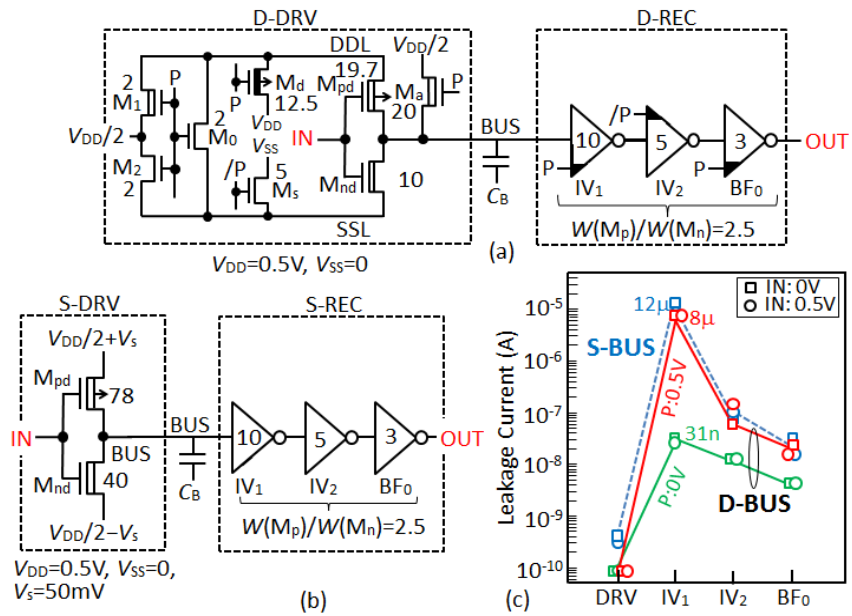

Fig. 8 Optimum sets of $W_{\mathrm{S}}$ for (a) D-BUS, and (b) S-BUS, and (c) leakage current of each stage for the optimum set. Numeral denotes $W(\mathrm{x} 80 \mathrm{~nm})$ for DRV, while $W(\mathrm{x} 80 \mathrm{~nm})$ for nMOSFET in REC. 
effective noise on BUS that decreases with increasing $W\left(\mathrm{M}_{\mathrm{n}}\right)$, the noise is $25 \mathrm{mV}$ for $W\left(\mathrm{M}_{\mathrm{n}}\right)=10 \times 80 \mathrm{~nm}$. Based on the results, optimum sets of $W \mathrm{~S}$ for D-BUS and S-BUS are exemplified in Figs. 8(a) and (b). Leakage currents for inputs " 0 " and " 1 " of each stage for the sets are shown in Fig. 8(c). In the active mode, the total current is almost dominated by $\mathrm{IV}_{1^{-}}$ current that is as large as $12 \mu \mathrm{A}$ and $8 \mu \mathrm{A}$ for S-BUS and DBUS with $P$ at $0.5 \mathrm{~V}$, respectively. In the standby mode, however, $\mathrm{IV}_{1}$-current is drastically reduced to $31 \mathrm{nA}$ with $\mathrm{P}$ at $0 \mathrm{~V}$ for D-BUS, while it remains to $12 \mu \mathrm{A}$ for S-BUS. Note that the active current of D-BUS is almost halved to $4 \mu \mathrm{A}$ for a duty cycle of $50 \%$.

\section{Dummy BUS (DM-BSA)}

Dummy bus eventually governs performances of the whole architecture explained later, since the above-described bus operates under the control of dummy bus. Fig. 9 shows a proposed dummy bus architecture (DM-BSA) composed of a pulse generator PGR, a dummy driver $\mathrm{DRV}_{\mathrm{D}}$, a dummy bus $\mathrm{BUS}_{\mathrm{D}}$, a dummy receiver $\mathrm{REC}_{\mathrm{D}}$, another dummy receiver $\mathrm{REC}_{\mathrm{D}}$ at the near end, and a delay $(\tau)$. All the circuit blocks, except for PGR, use almost the same circuit configuration, structure, size, and layout, as the above-described D-BUS. Hence, two signal detecting points, corresponding to $\pm V_{\mathrm{s}}$, of the $\mathrm{IV}_{1}$ in the above-described D-REC are automatically tracked by the pulse from PGR even under variations of fabrication process, voltage including power-supply bounces, and temperature. As for PGR, triggered by a global precharge pulse $\mathrm{P}_{\mathrm{G}}$ and controlled by $\mathrm{BUS}_{\mathrm{D}}, \mathrm{REC}_{\mathrm{D}}$ at the near end, and the delay, it self-generates pulses for driving D-BUS. The ACC, however, is deleted due to no need for the operation. During long standby periods, $\mathrm{P}_{\mathrm{G}}$ turns off to make all the dummy bus and buses at a low leakage mode with the stacked MOSFETs off, benefitting hand-held equipment. Just after $P_{G}$ goes up to $0.5 \mathrm{~V}$, normal operations start. Hence, a NAND in PGR starts generating local pulses $\mathrm{P}_{\mathrm{N}}$ and $\mathrm{P}_{\mathrm{F}}$ with always turning on all the inverters in $\mathrm{REC}_{\mathrm{D}}$ (thus static operations with $\mathrm{P}_{\mathrm{G}}$ at $0.5 \mathrm{~V}$ ), while performing dynamic operations for
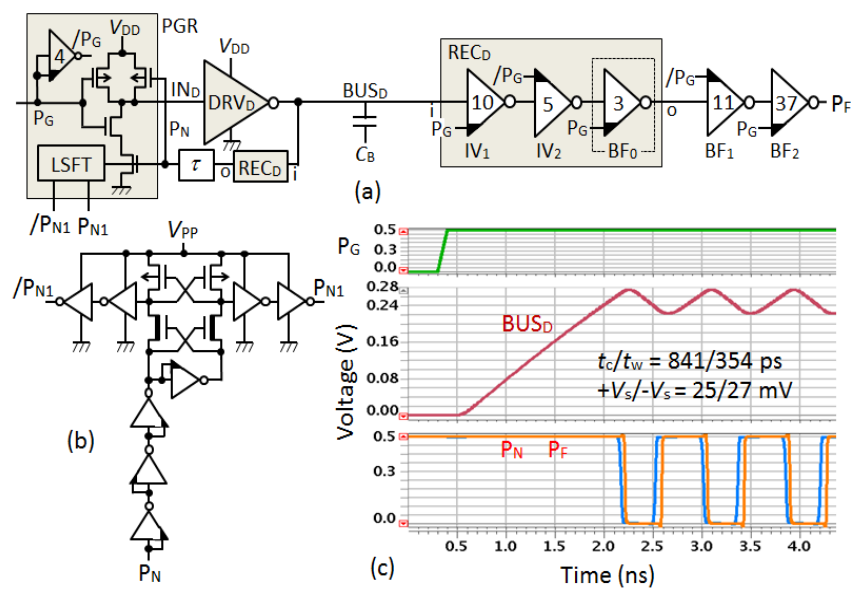

Fig. 9 (a) Dummy bus architecture (DM-BSA), and (b) level shifter (LSFT), and (c) waveforms using $W s$ optimized for D-DRV and DREC. the inverters in D-BUS. Note that $\mathrm{P}_{\mathrm{N}}$ and $\mathrm{P}_{\mathrm{F}}$ correspond to $\mathrm{P}$ in the previous figures (e.g., Fig. 2). Separated $\mathrm{REC}_{\mathrm{D}} \mathrm{S}$ at the near end and the far end make the design of the architecture simple and robust, enabling to cancel the bus delay effect. Hence, the one at the near end can generate pulse $\mathrm{P}_{\mathrm{N}}$ to control DRVs at the near end (see Fig. 11), independently of the other $\mathrm{REC}_{\mathrm{D}}$ controlled by pulse $\mathrm{P}_{\mathrm{F}}$ at the far end. Even for the dummy bus, noise on $\mathrm{BUS}_{\mathrm{D}}$ must be reduced since it determines the necessary $V_{\mathrm{s}}$ on $\mathrm{BUS}_{\mathrm{D}}$. If power-supply noise is negligible with noise reduction techniques described later, the tolerable total noise on $\mathrm{BUS}_{\mathrm{D}}$ is $25 \mathrm{mV}$, equal to $V_{\text {off }}(\mathrm{REC})$, since $\mathrm{ACC}$ is deleted.

A level shifter LSFT generates pulses $\mathrm{P}_{\mathrm{N} 1}$ and $/ \mathrm{P}_{\mathrm{N} 1}$ to drive $\mathrm{D}$ DRVs in Fig. 2. It features using gate-source differentiallydriven ZVT-MOSFETs for quickly shifting a $0.5-\mathrm{V} \mathrm{P}_{\mathrm{N}}$ to $V_{\mathrm{PP}}$ $(=1 \mathrm{~V})$ pulse $\mathrm{P}_{\mathrm{N} 1}$. Tapered- $W$ inverters [11] are used to drive a large capacitance coming from 32-buses with small area and low power. $V_{\mathrm{PP}}$ can be generated with a well-known on-chip voltage doubler. Fig. 9(c) illustrates simulated waveforms. BUS $_{\mathrm{D}}$ builds up from $V_{\mathrm{SS}}$ after $\mathrm{P}_{\mathrm{G}}$-activation and starts to oscillate at a cycle $t_{\mathrm{c}}$ of $0.84 \mathrm{~ns}$ and a $V_{\mathrm{s}}$ of $\pm 25-30 \mathrm{mV}$ that is smaller than the above-described noise. From the waveforms, the bus delay is about $0.42 \mathrm{~ns}$, which is the same as that for DBUS due to the same circuit. The $V_{\mathrm{s}}$ and cycle time $t_{\mathrm{c}}$ of dummy bus are adjustable with $W\left(\mathrm{M}_{\mathrm{nd}}\right)$ in $\mathrm{DRV}_{\mathrm{D}}$ and a delay $(\tau)$, respectively, as shown in Fig. 10.
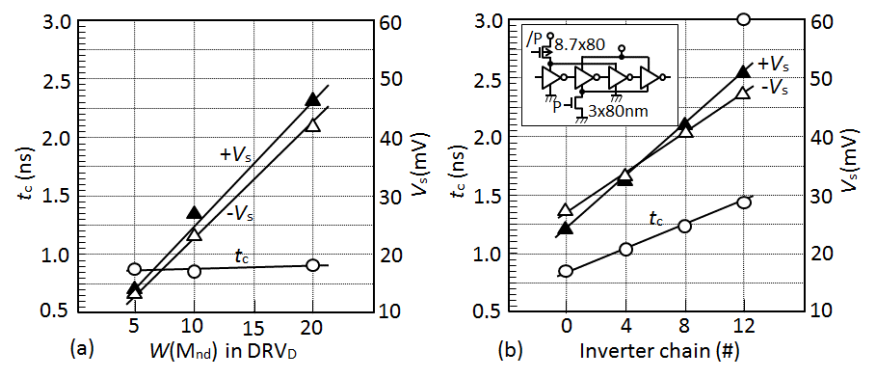

Fig. 10 Characteristics of dummy bus (a) without delay, and (b) with delay $(\tau) . t_{\mathrm{c}}$; cycle time, $\pm V_{\mathrm{s}}$; signal swing on dummy bus.

\section{Application to 32-bit Buses}

\section{A. Architecture and Performances}

Fig. 11 shows a 32-bit D-BUS architecture, in which optimum parameters in Fig. 8 for D-BUS and Fig. 9 for dummy bus (DM-BSA) are used to ensure high speed and stable operations. Taper CMOS buffers [11], $\mathrm{BF}_{1}$ and $\mathrm{BF}_{2}$ in DM-BSA, and buffers $\mathrm{BF}_{0} \mathrm{~S}$ in each REC enable to reduce the load capacitance of $\mathrm{REC}_{\mathrm{D}}$ and the $\mathrm{P}_{\mathrm{F}}$-capacitance that is usually large because one dummy bus commonly controls 32 buses. Fig. 12 illustrates simulated waveforms. A 1-pF BUS operates successfully at $0.5-\mathrm{V} 0.84-\mathrm{ns}$ cycle $(1.2 \mathrm{GHz})$, as expected, and as mentioned in detail below. Note that if the signal discrimination levels for " 1 " and " 0 " are $V_{\mathrm{DD}} / 2(=0.25$ $\mathrm{V})$, an input pattern of " 0 " " 1 " " 0 " " 1 " starts to be discriminated at point $\mathrm{S}$ at each cycle. In addition, since the output $\left(\mathrm{OUT}_{0}\right)$ becomes invalid at point $\mathrm{T}$ when it starts to be 


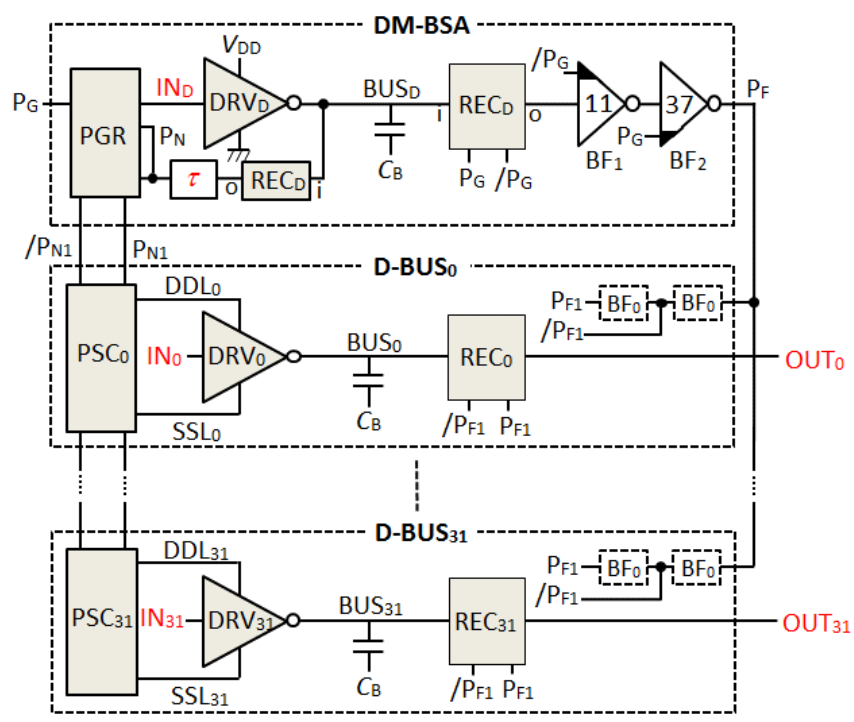

Fig. 11 32-bit bus architecture using D-BUS and DM-BSA. BF is $_{0}$ in Fig. 9.

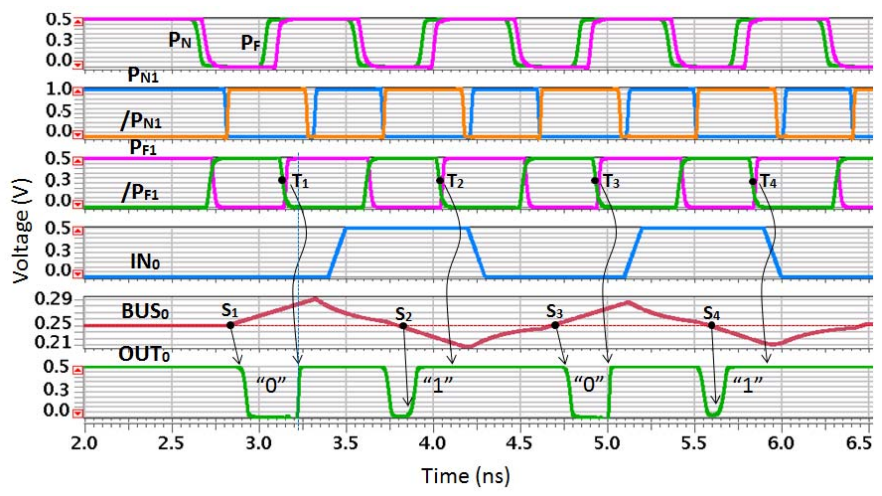

Fig. 12 Waveforms of the 32-bit architecture.

precharged to $0.5 \mathrm{~V}$ by $/ \mathrm{PF}_{1}$. Therefore, $\mathrm{OUT}_{0}$ is valid between $\mathrm{S}$ and $\mathrm{T}$ at each cycle. Despite spurious outputs due to incomplete BUS-precharging and a high gain of IV1, the input pattern is successfully transmitted to $\mathrm{OUT}_{0}$, as seen in the figure. Obviously, $V_{\mathrm{s}}$ is $30-40 \mathrm{mV}$ on $\mathrm{BUS}_{0}$, which are larger than the assumed noise $(=25+5=30 \mathrm{mV})$, thus ensuring stable operations. Such high-speed and stable operations, however, are never realized without reducing the following power-supply-noise in the architecture.

\section{B. Noise Reduction}

Fig. 13 shows noise sources, related to power-supply bounces in D-BUS, and the reductions. For example, to reduce an inaccurate $V_{\mathrm{DD}} / 2$ DC-level from an on-chip generator (HVG), laser trimming of the poly-Si resistors, well established for memory repair [12], is effective. A transient fluctuation may occur at the $V_{\mathrm{DD}} / 2$ line due to shortage of the driving capability of $\mathrm{HVG}$, when $\mathrm{P}_{\mathrm{N}}$ (i.e., $\mathrm{P}$ in Figs. 2 and 8(a)) inputted to ACC drives a large BUS capacitance. However, it may quickly recover if $\mathrm{HVG}$ enables to detect the fluctuation, followed by feedback for stabilization [13]. Ideally, the $\left(V_{\mathrm{DD}}+V_{\mathrm{SS}}\right) / 2$ level of each PSC, ACC, and REC must be always equal statically and dynamically to the $V_{\mathrm{DD}} / 2$
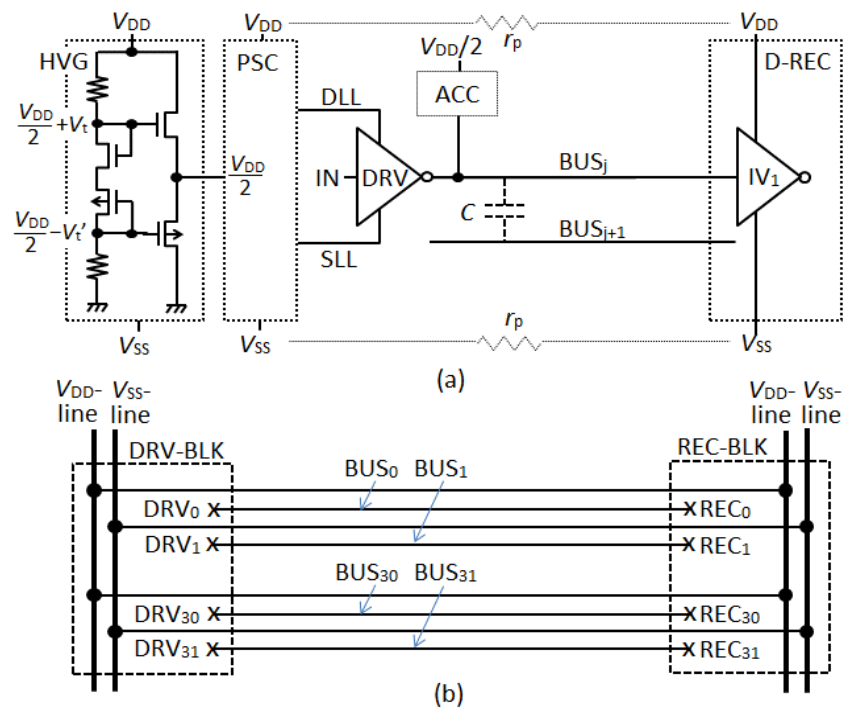

(a)

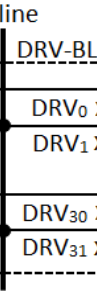

$V_{D D}-V_{S S}$ line line

Fig. 13 (a) Noise sources, and (b) shielded BUS with $V_{\mathrm{DD}}$ and $V_{\mathrm{SS}}$ lines. $\mathrm{HVG} ; V_{\mathrm{DD}} / 2$-genarator [13].

level from HVG. Otherwise the difference works as noise, thus calling for a tight and close layout of relevant circuits with wide-enough power lines. This is also the case for each $V_{\mathrm{DD}}$ line and each $V_{\mathrm{SS}}$ line. In general, however, it is usually difficult to reduce the $V_{\mathrm{DD}^{-}}$and/or $V_{\mathrm{SS}^{-}}$level difference between the near end (e.g., PSC) and far end (e.g., D-REC) due to small parasitic resistances $\left(r_{\mathrm{p}} \mathrm{s}\right)$ between them. In addition, there exists line-to-line BUS coupling. A bus-line shielding scheme proposed in Fig. 13(b) may reduce not only the level difference with effectively wide enough power lines, but also the line-coupling. Fig. 14 illustrates the layout of the 32-b architecture incorporating the shielding scheme. The BUS-M3-metal line pitch is $600 \mathrm{~nm}$ with a width of $100 \mathrm{~nm}$ for BUS and power lines and a space of $200 \mathrm{~nm}$. A bus capacitance of $1 \mathrm{pF}$ comes from a bus line of about $20 \mathrm{~mm}$ long. Area overhead by D-BUS is only $6.7 \%$ for a given BUS pitch.

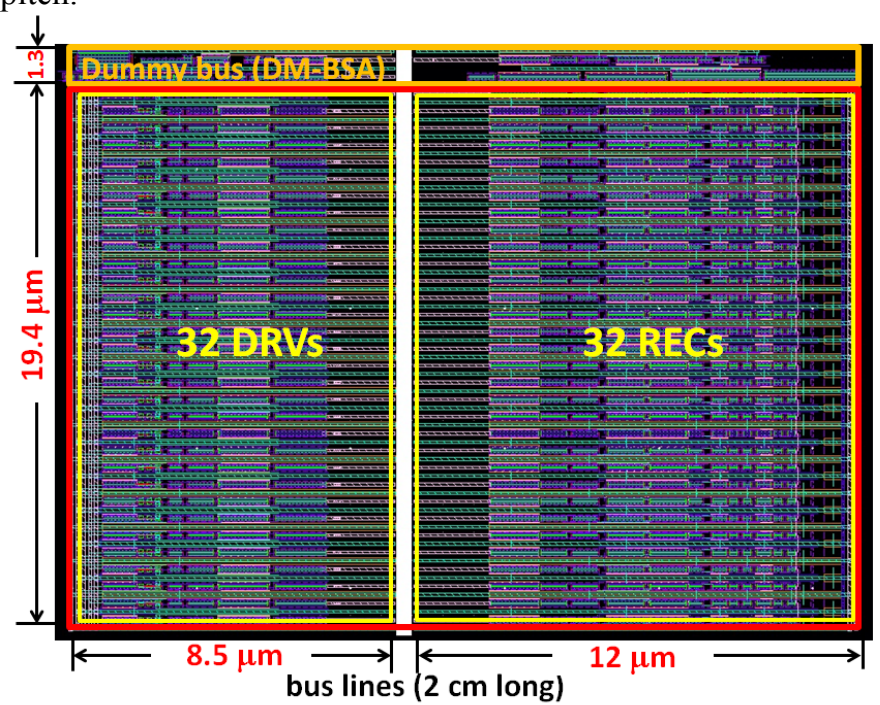

Fig. 14 Layout of 32-bit bus architecture with optimum parameters in Figs. 8 and 9. 


\begin{tabular}{|c|c|c|c|c|}
\hline & & Proposed(D-BUS) & Conv. (S-BUS) & Remarks \\
\hline \multicolumn{2}{|c|}{$V_{t}\left(M_{n d}\right)$} & LVT(254 mV) & LVT & Fig.8 \\
\hline \multicolumn{2}{|c|}{$W\left(\mathrm{M}_{\mathrm{nd}}\right) / W\left(\mathrm{M}_{\mathrm{n}}\right)$} & $10 / 10 \times 80 \mathrm{~nm}$ & $40 / 10 \times 80 \mathrm{~nm}$ & Fig.8 \\
\hline \multicolumn{2}{|c|}{ BUS swing $\left( \pm V_{s}\right)$} & $\pm 50 \mathrm{mV}$ & $\pm 50 \mathrm{mV}$ & \\
\hline \multirow{2}{*}{$\begin{array}{l}\text { Typ. } \\
\text { speed } \\
\text { (ratio) }\end{array}$} & Delay & $\cong 0.42 \mathrm{~ns}(0.17)$ & $\cong 2.5 \mathrm{~ns}(1)$ & $C_{B}=1 p F$, Fig. 9 \\
\hline & Cycle time & 0.84 ns (0.34) & $\cong 2.5 \mathrm{~ns}(1)$ & $C_{B}=1 \mathrm{pF}$, Fig. 9 \\
\hline \multirow{2}{*}{$\begin{array}{l}\text { Leakage } \\
\text { current }\end{array}$} & Active & $144 \mu \mathrm{A}$ & $384 \mu \mathrm{A}$ & $\begin{array}{l}\text { Fig.8, } \\
\text { duty } 50 \%\end{array}$ \\
\hline & $\begin{array}{c}\text { Standby } \\
\text { DM-BSA }\end{array}$ & $\frac{1.1 \mu \mathrm{A}}{62 \mathrm{nA}}$ & $\begin{array}{c}384 \mu \mathrm{A} \\
- \\
\end{array}$ & $\begin{array}{l}\text { Fig.8, } \\
\text { PG }_{0} \text { O V }\end{array}$ \\
\hline \multicolumn{2}{|c|}{ Area overhead } & $6.7 \%$ & 0 & Fig.13 \\
\hline \multicolumn{2}{|c|}{ On-chip converters } & $0.25 \mathrm{~V}, 1 \mathrm{~V}$ & $0.2 \mathrm{~V}, 0.3 \mathrm{~V}$ & \\
\hline
\end{tabular}

Fig. 15 Performances of 0.5-V 32-bit D-BUS architecture, compared with the conventional.

\section{Summary}

Fig. 15 compares performances between the proposed 32b D-BUS and the conventional 32-b S-BUS, assuming that power-supply noise becomes negligible with noise-reduction techniques. Note that the D-BUS realizes a short delay of about $0.42 \mathrm{~ns}$ and a fast cycle time of $0.84 \mathrm{~ns}(1.2 \mathrm{GHz})$ with x3-5 faster than the S-BUS. For a more realistic bus length of $1 \mathrm{~cm}$, the cycle is doubled to $2.2 \mathrm{GHz}$. In addition, the total DC current in the active mode, dominated by $\mathrm{IV}_{1}$-current, is 144 $\mu \mathrm{A}$ for D-BUS and $384 \mu \mathrm{A}$ for S-BUS. The current in the standby mode is $1.1 \mu \mathrm{A}$ only for D-BUD while $384 \mu \mathrm{A}$ for SBUS, with more than two-order reduction with D-BUS.

\section{Conclusion}

To achieve a $0.5-\mathrm{V}$ low-power high-speed robust bus, a dynamic bus architecture, combined with a dynamic driver and a dynamic receiver for small leakage current with stacked MOSFETs, was proposed. In particular, the dynamic driver enables high speed even at $0.5 \mathrm{~V}$ with increased gate-overdrive by changing the power lines from $V_{\mathrm{DD}} / 2$ in the standby mode to $V_{\mathrm{DD}}$ in the active mode. It further speeds up with the help of another proposal of a dummy bus for tracking the busvoltage detecting points for reducing the bus swing. Robustness of each proposal was investigated by Monte Carlo simulation. Then, a $0.5-\mathrm{V}$ 28-nm-FD-SOI 32-bit bus architecture using the proposals was evaluated by simulation. The power-supply bounce noise and the reduction were also investigated through the layout. As a result, it turned out that the architecture has a potential of operating a $1-\mathrm{pF}$ bus at a 50 $\mathrm{mV}$ swing, $1.2 \mathrm{GHz}$, and a standby current of $1.1 \mu \mathrm{A}$, with $\mathrm{x} 3-$ 5 faster and more than two-order lower standby current than the conventional static architecture.

\section{Acknowledgement}

The authors thank Circuit Multi Projects (CMP), Grenoble, France for providing the FD-SOI $28 \mathrm{~nm}$ design kit (DK), and STMicroelectronics, Crolles, France for the DK support.

\section{References}

[1] D. Liu and C. Svensson, "Power consumption estimation in CMOS VLSI chips," IEEE J. Solid-Sate Circuits, vol. 29, pp.663-670, June 1994.

[2] T. Sekiguchi, K. Ono, A. Kotabe, and Y. Yanagawa, "1-Tbyte/s 1-Gbit
DRAM architecture using 3-D interconnect for high-throughput computing," IEEE J. Solid-State Circuits, vol. 46, no. 4, pp. 828-837, Apr. 2011.

[3] Y. Nakagome, K. Itoh, M. Isoda, K. Takeuchi, and M. Aoki, "Sub-1-V swing internal bus architecture for future low-power ULSI's," IEEE J. SolidState Circuits, vol. 28, pp. 414 -419, Apr. 1993.

[4] A. Katoch, H. Veendrick, and E. Seevink, "High Speed Current-mode Signaling Circuits for On-Chip Interconnects," in Proc. IEEE Int. Symp. Circuits Syst., 2005, pp. 4138-4141.

[5] H. Zhang, V. George, and J. M. Rabaey, "Low-Swing On-Chip Signaling Techniques: Effectiveness and Robustness," IEEE Trans. VLSI Systems, vol. 8, No.3, pp. 264-272, June 2000.

[6] C. Svensson, "Optimum Voltage Swing on On-Chip and Off-Chip Interconnect," IEEE J. Solid-State Circuits, vol. 36, No.7, pp. 1108-1112, July 2001.

[7] Eric Karl et al., "A 0.6V 1.5GHz 84Mb SRAM Design in 14nm FinFET CMOS Technology," ISSCC Dig. , pp. 310-311, Feb. 2015.

[8] N. Sugii, "Low-power-consumption fully depleted silicon-on-insulator Technology," Microelectronic Engineering 132(2015)226-235.

[9] P. Flatresse, et al., "Ultra Wide Body Bias Range LDPC decoder in 28nm UTBB FDSOI Technology”, ISSCC Dig., pp. 424-425, Feb. 2013.

[10] S. G. Narendra and A. Chandrakasan, Leakage in Nanometer CMOS Technologies, Springer, 2005.

[11] S. R. Vemuru and A. R. Thorbjornsen, "Varible-Tapaer CMS Buffere," IEEE J. Solid-State Circuits, vol. 26, No.9, pp. 1265-1269, Sept. 1991.

[12] K. Itoh, VLSI Memory Chip Design, Springer, 2001.

[13] Y. Nakagome et al., "An Experimental 1.5-V 64-Mb DRAM," IEEE J. Solid-State Circuits, vol. 26, No.4, pp.465-471, April 1991. 